\title{
Factors for the Acceptance of Enterprise Resource Planning (ERP) Systems and Financial Performance
}

\author{
Ayman Bazhair and Kamaljeet Sandhu
}

\begin{abstract}
The purpose of this research paper to present the synthesized theoretical and empirical literature to help in the development of propositions and suggestions of a research agenda on the acceptance of ERP systems and their link with financial performance, the paper develops the technology acceptance model (TAM) to synthesize relevant literature and to develop proposition for future research agendas. The proposition and the research agenda will provide an adequate explanation of the acceptance of ERP systems, and their possible association with financial performance of organizations. The literature does provide a canon of acceptance of ERP systems in relation to financial performance. This research provides a positive association between the acceptance of ERP systems and financial performance. Also, the use of TAM theory provides further insight into identifying the acceptance factors of ERP.
\end{abstract}

Index Terms-Technology acceptance model, organizational performance, corporate performance, ERP, financial performance.

\section{INTRODUCTION}

The use of the ERP systems and the ways in which the organizations adopt them has been widely researched [1]-[6]. The adoption process which the organization undertake seems to focus on the different types of needs of the user and the ways in which the organization is able to satisfy the needs of the user [7]-[9], [3], [10]. However, the research focus of these issues seems to ignore one of the key concerns for any organization. This concern is based on a return on the investments which organizations undertaken during the adoption of any system by in particular ERP systems. The link between the financial performance and the acceptance of the ERP systems seems to be unclear, as most of the research only focus on the so called 'other' need of the user and the organizations. However, the underlying fact remains that the adoption of ERP systems is linked to the ability of the organization to gain financial returns from the system, and any model which does not take this fact into account is missing a significant link in the adoption process. This research paper investigates the link between the issues which the user faces with the financial performance of the organization during the adoption of ERP systems. One of the key values of this research is to suggest future research agenda for the ERP adoption research, which should take into account the tangible and intangible rewards

Strategic benefits of the ERP adoption can be a critical

Manuscript received July 7, 2013; revised October 10, 2013.

Ayman Bazhair is with the University of New England, Australia (e-mail: abazhair@myune.edu.au). mistake from managers, as they would not realize that they have missed a crucial benefit of the system. This research uses the technology acceptance model to understand the main components of the acceptance of new technologies such as ERP systems in organizations. However, the implementation of these systems is then balanced against the financial needs of the organizations to operate in a profit making environment. This would mean that the needs of the user are paramount; however the financial needs of the organization cannot be ignored if the adoption of the ERP is to be a success.

This research article aims to develop a deeper understanding of the theoretical and empirical literature on ERP adoption, and its link with the financial performance of the organization. The aim of the research is to propose a research agenda which would provide adequate explanations of the adoption of ERP systems in organization, while also explaining and dissecting the financial needs of the organizations within the system development context. This has been identified as a major gap in the research area and this article attempts to bridge this gap. The structure of the paper is as follows. In section two, the theoretical underpinning of the ERP adoption are presented, which explain the link between ERP and the technology acceptance model. Section three of the paper examines the literature on ERP adoption within the context of the user needs and the financial needs of the organization. Section four analyses the literature, and proposes five main propositions to understand the dynamics of the link between financial performance and the ERP adoption in organizations. Section six of the paper presents the finding and conclusions of the research, and proposes that a balance between the financial needs of the organization with the user satisfaction needs to be achieved for the successful ERP adoption. One of the significant conclusions of the research is that the benefits the users receive from the implementation of ERP systems can also lead to financial performance increase, and therefore both the factors are interlocked and dependent on each other. A number of other possible significant propositions of the research suggest that the user training and education are also critical to the understanding of ERP implementation. Other issues such as change management also seem to be significantly important for a future research agenda on ERP implementation. A significant limitation of the research agenda of academics seems to be a lack of understanding of the link between the financial performance of the organization with the adoption of ERP, and this research articles attempts to examine these issues in more detail. 


\section{THEORETICAL FrAME WORK}

\section{Technology Acceptance Model}

We propose the use of the technology acceptance model as a theoretical position which can examine the acceptance of Enterprise Resource Planning (ERP) systems in organizations. A growing body of knowledge in the academic research seems to point out that the adoption of information technology and its utilization among users is based on the theory of technology acceptance model (TAM). TAM model is of the view that the perceived usefulness and ease of use of IT are the major determinants of the usage of new systems [11]. Based on this original definition, it has been argued that the research on the acceptance of technology would need to address how the different variables affect the main variable of TAM, which are usefulness, ease of use attitude and user acceptance [12]. However, it appears that limited attention has been given by the literature on understanding the factors which have influenced the perceived usefulness and ease of use of these systems [12]. One of the most significant measures which have been used to measure the implementation success is the achieving of the intended use of information Technology (IT). The usage of the system not only respects the acceptance of the technology by user, but also links as a basis of the research on the behavioral issues and the use of IT [12]. The technology acceptance model posits that the process of the diffusion of the system is closely associated with the way in which the innovations are viewed by the users [11]. The diffusion of the system in an organizational environment, and will be based on the in which the adopters of the new can appreciate the changes in the system [11]. The adoption process of a system could have a number of different stages, which people use to ensure that the system is fully part of the organizational environment [13]-[15]. These adoptions of new technologies, according to the technology acceptance model can be significantly important for organizations as they ensure that the user of the system is able to take up the use of the system in an efficient and effective manner, leading to organizational benefits of the system [14], [7], [16].

The perceived usefulness of a system, also has a direct relationship with the acceptance of the system, and can directly influence the way in which the organizations can implement new systems [17]. The link between the acceptance of the technologies in the organization, and the way systems are implemented can lead to resistance of change issues, which users can find increasingly difficult to deal with, as political issues as a well as institutional factors can influence this resistance of the systems [18]. The way users accept the new technology is often also based on the political settings within the organization, and therefore can influence the perceived benefits of any new system [19]-[21]. There is evidence to suggest the way in which the benefits are perceived is also linked to the response which users give to training and support for the new system, and therefore there is a need for proper communication to initiate and lower the possible resistance to change [16], [12].

Another key element of the Technology acceptance model is the way in which the financial performance is linked to the way in which new systems are adopted. The financial and economic benefits of adopting new systems have been established [19], [22]. However, the costs of a lack of acceptance of new systems has also been mentioned as one of the most significant reason for a need for managers to be careful about the way in which the deal with the acceptance of new technologies, as the possible economic ramifications of the failure of technological systems can be significant [23], [24]. The negative impact of the failure of systems can be significant, especially in the modern era as organizations are increasingly using information systems to gain and sustain a competitive advantage, and as the systems are becoming the integral part of the information systems in the organization [25], [26]. There issues are also important for managers, as they want to ensure that they are able to develop a deep understanding of the needs of their employees, and ensure that they put into practice those systems which motivate the employees, and can therefore improve the financial performance of the organization [27].

\section{LITERATURE REVIEW}

The use of enterprise resource planning systems in different organizations has been widely researched. These studies, have in general examined ERP systems as encompassing a set of activities, which are based on the different kind of software's and having an effect on managing the different resources of the organization in an effective manner [15]. One of the critical importance of the system has been linked with the way the changing processes in the organization at the advent of information system have also led to the implementation of the ERP system in the organization. The ways in which the ERP systems are adopted are increasing important for organization, as they tend to invest large amounts into these systems, and expect a return in form of increased efficiency and effectiveness of the organizational actors [28]-[30]. The implementation of these systems is also critical as the organizations seek to gain a sustainable competitive advantage from these systems, and they seek to ensure that the system implementation is carried out in a suitable manner [31], [5].

The financial and economic benefits of the ERP complementation have generally been one of the significant reason for the adoption of ERP system by organizations [30], [5]. However, the ways in which the employees and users of the system adopt are not always based on the cost factors alone, and are dependent on a number of other issues. These issues have a significant link between the financial performance of the company and the different factors which lead to the adoption of ERP system by the user [32]-[34]. The link between these 'other' factors and the financial performance of the organization has not been clearly addressed in the literature and this seems to be a significant gap in the literature. The link between the technology acceptance model and the conceptual model is also critically important, as the main issues in the theoretical model are some of the most important aspects of the TAM. This review of literature is based on testing a number of propositions, and to examine how these have been addressed in the literature, which aims to explain our research model (see Fig. 1): 


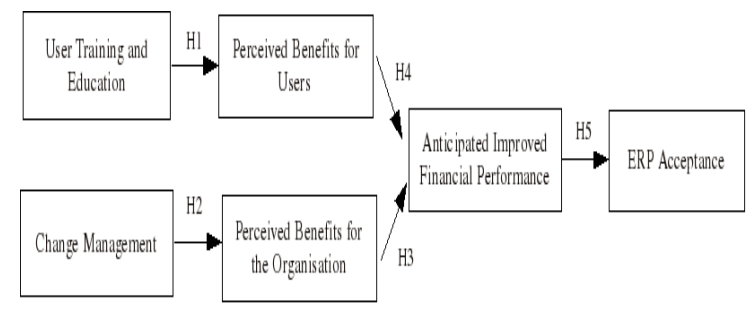

Fig. 1. Model for acceptance of ERP.

\section{A. User Training and Education's Influence on Perceived Benefits of User}

One particular aspect of the adoption of technology in general, and the adoption of ERP in particular is the way in which the users have been able to adopt new technologies [35], [14], [7], [8]. The benefits that the user perceives from a particular system have, according to a number of studies been associated with the training that they receive and the level of education of the user [36], [37]. The perceived benefits of the user who is adopting a new system are also linked with the needs of the senior managers in developing systems which are easier for users to use, and the cost effectiveness of the system is also increased with the less training required. The training and learning environment is no longer seen as a individual process, and the need for managers to establish collective learning and training session for ERP system have also been clearly established [38]. For example, one reason was to examine the ways in which web based learning and training was substantially important for users, and the way they were able to improve their cognitive processes was also established [38].

The user training is also important as a part of the technology acceptance model, as it allows the different components of the systems to be properly accepted by the different users. This in particular allows the users to ensure that they can use the system, and bring in financial benefits to the system [16]. This particular element of the system is also necessary as it would allow the different actors in the organization to work in unison, leading to significant improvements in the effectiveness of the organization. This particular view of TAM is also necessary as it can lead to many different ways in which the employees can react, and therefore the different aspects need to be taken into account [39], [40].

\section{B. Change Management and ERP Benefits for Users}

Another critical factor which has been identified in the literature is the ways in which change management is dealt with by the senior management. Change management has been linked extensively with the [13], [41]-[43]. One of the major issues which the literature deals with in regards to the change management is the way in which the user resists the new systems. The resistance to change theme has been prevalent in the early literature of ERP implementation, and has continued to be one of the recurring themes which has been regarded as important by the literature [42], [43]. The human aspect of change management is related to the loss of jobs and lack of information regarding new systems, and this is true for any system as well as ERP systems[44].The change management aspects of the system implementation not only examine the aspects of the perceived benefits for the organization, but also the user of the system. In many cases, research suggests that organizations are unwilling to implement a new system because of high level resistance. This resistance at the board or senior management levels was mostly due to the senior managers feeling insecure about their jobs or status, and therefore resisted changes in the organizational setup[45], [6].

Another significant aspect in the change management literature has compared the organizational as compared to the personal benefits that the users accrue due to the use of the new systems [46]. In many cases today it is safe to assume that organizations have reconciled their issues with new systems, and there is wide spread acceptance of new systems as brining both structural as well efficiency benefits to the organizations [43], [6]. However, the main problems of user acceptance of new systems as a change initiative is at the cultural and behavioral level, where the user resists the change in a system because they feel insecure from the system, or unable to be properly training to use new and innovative systems[42], [46]. This human aspect of the change process is also critical as the user is the ultimate success factor for an ERP system, and can bring organization wide changes in the culture of the organization, which can lead to wider benefits for the organization [44]. However, it is difficult to examine the ways in which the change management process can be reconciled in the case of wider systems such as ERP, which creates a significant research gap for the academic literature. Another main issue which managers face when dealing with change management is that the reduction in the resistance to change can lead to significant organizational benefits, as the systems would be used in a more constructive manner [47]. A positive behavioral approach of the working force in an organization will also mean that the efforts of the managers will be served on improving the system according to the organizational needs, and the human elements will not be a major issue of concern for the managers [47].

\section{Benefits for Organization and Financial Performance}

The organizational benefits of ERP implementation have been widely discussed in the literature [48]-[52]. These benefits have generally been categorized into two main aspects being the tangible benefits and the intangible benefit. Tangible benefits are the direct reduction in costs which have been brought about by the implementation of ERP systems in organizations [49], [53], [51] Particularly important for organization is to realize that the intangible benefits from a system are the most critical component of the ERP implementation [4]. Some of the intangible benefits of the system are based on issues such as reduced headcount of the organization, improved decision making of the organization, reduced number of complaints of the customers and the increased availability of the information to the managers using the ERP in organizations [4].

The intrinsic value of the beneficiates which organizations realize are highly difficult to quantify in cases where the fast changing markets make it impossible to measure the benefits [4]. This creates new issues for organizations, as most are unsure about the true benefits of ERP systems. The intangible benefits from an ERP system have been categorized to be 
based on the ongoing benefits and future benefits of the systems. The ongoing beneficiates of systems may be based on issues such as improvements to the processes, workflow and the information access that managers have in relation to a particular system [4]. Other ongoing benefits of ERP systems to the organization may be based on the level of customer services that they can deliver to the end user, which has a higher quality and support for the customer [4]. However, more difficult to measure for the organization is in relation to the future benefits of the system. These future benefits are not only hard to realize but also are hard to measure. For example one of the critical benefit of the ERP system has been to enable the organization to have the foresight to develop new markets, products and services, which enable the organization to change according to the changes in the market environment [4]. These benefits can be divided into the strategic, tactician and operational benefits for the organization, based on the way they can structure their ERP systems [4]. Some have argued that ERP investments are strategic in nature, and fulfil the goal of the organization in the longer term [4], [15].

\section{Benefits for User and Financial Performance}

The perceived benefits for the user have also been investigated by the literature [14], [15], [3]. The user satisfaction has been used traditionally as one of the key benchmark for the increased benefits for the users of the ERP systems [8], [9], [3]. The ERP adoption is linked to the training and perceived benefit needs of the user, who are mostly related to the need of the system to be easy to use, accessible and reliable (Chen et al., 2008). One of the key measures of the satisfaction of the ERP system is based on the needs of the end user to develop affection with the system and to be a supporter of the development process of the system. This is highly important as it enables the organization to deliver systems which are needed by the user and increases the benefits of the system for the user [7]. The financial performance of the system is also linked to these factors as the increased use of the system can lead to better use of resources, leading to the increased benefits of the systems in the long run for the organization [7].

Other user benefits linked with the adoption of the ERP system is that the cultural needs of the user needs to fulfill by the ERP system. The increased fulfilling of these intrinsic needs of the user will enable the user to use the system consistently. And will ensure that the system does not fail [54]. This will also ensure that a running system is also critically successful for the organization and leading to the financial benefits of this system. The failure of these system can also be a major financial loss for the organization, as the costs of the use of the system may not fall, which would mean that the organizational changes would not success, leading to increased costs for the organization [29], [30], [5]. The benefits of the adoption of the ERP systems for the users are part of the TAM, and need to be taken into account by the managers when developing the needs of the different users. This is in particular needed, as a link between the TAM and the benefits of the users is direct [55], [56], as many different users are able to accept a technology, and they benefit from it in the long run.

\section{E. The Impact of Financial Performance on ERP Acceptance}

The impact of higher financial performance of an organization on the ERP adoption has also been studied [57]. One of the core applications of the ERP systems have traditionally been financial management, and within an enterprise this focus has been on the capital flow of good [57]. The ways in which the target of the financial management has been on the enterprise capital good, similarly, the ERP systems have also been designed to service these needs [57]. The financial performance of a firm, when higher than previously also leads to the development of newer ERP systems, as the business managers can justify the cost of expensive systems which are delivering results for the organization [57]. Within the debate on the financial performance (See Table I), and its impact on the adoption of the ERP system, organizations also tend to take the aspects of tangible and intangible results on their investments very seriously too [57]. One of the key determinants in whether a firm adopts the ERP system or not depends on the way it perceives the value it gets from that particular system [58], [59].

TABLE I: SYNTHESIZED THE KEY LITERATURE FROM THIS SURVEY

\begin{tabular}{|c|c|c|c|}
\hline $\begin{array}{c}\text { Author of } \\
\text { Study }\end{array}$ & Method & Sample & $\begin{array}{c}\text { Study focus and } \\
\text { findings/conclusions }\end{array}$ \\
\hline $\begin{array}{c}\text { (Amoako- } \\
\text { Gyampah, } \\
2007)\end{array}$ & Mail Survey & 571 & $\begin{array}{l}\text { The focus of study was on } \\
\text { managerial effort on } \\
\text { increased the perceptions of } \\
\text { users. The results suggest } \\
\text { that personal relevant to } \\
\text { technology will contribute } \\
\text { to implementation success }\end{array}$ \\
\hline $\begin{array}{l}\text { (Chang } e t \\
\text { al., 2008) }\end{array}$ & Questionnaire & 600 & $\begin{array}{l}\text { Proposal of a conceptual } \\
\text { model to understand the } \\
\text { adoption of ERP systems by } \\
\text { employees }\end{array}$ \\
\hline $\begin{array}{l}\text { (Markus et } \\
\text { al., 2000) }\end{array}$ & $\begin{array}{l}\text { 1: reviews of } \\
\text { published and } \\
\text { in-process } \\
\text { research } \\
\text { studies and } \\
\text { teaching } \\
\text { cases of ERP } \\
\text { implementati } \\
\text { ons } \\
2 \text { in-depth } \\
\text { case studies } \\
3: \text { Interviews }\end{array}$ & $\begin{array}{l}12 \text { case Studies } \\
11 \text { Interviews }\end{array}$ & $\begin{array}{l}\text { Early identification of the } \\
\text { problems of ERP } \\
\text { implementation are } \\
\text { significantly important }\end{array}$ \\
\hline $\begin{array}{l}\text { (Chen } \text { et } \\
\text { al., 2008) }\end{array}$ & Questionnaire & N/A & $\begin{array}{l}\text { ERP users should focus on } \\
\text { their actual needs, and } \\
\text { select their suppliers } \\
\text { carefully. }\end{array}$ \\
\hline $\begin{array}{l}\text { (Foster } \text { et } \\
\text { al., 2008) }\end{array}$ & Survey & 208 & $\begin{array}{l}\text { Large scale implementation } \\
\text { of ERP is highly complex, } \\
\text { and have a long reaching } \\
\text { impact on the } \\
\text { organizational set ups. }\end{array}$ \\
\hline $\begin{array}{l}\text { (Murphy } \\
\text { and Simon, } \\
\text { 2002) }\end{array}$ & Case Study & 1 & $\begin{array}{l}\text { Information systems highly } \\
\text { difficult to quantify } \\
\text { intangible terms }\end{array}$ \\
\hline $\begin{array}{l}\text { (Hong and } \\
\text { Kim, 2002) }\end{array}$ & $\begin{array}{l}\text { Interviews } \\
\text { questionnaire }\end{array}$ & 160 & $\begin{array}{l}\text { ERP implementation } \\
\text { success primarily depends } \\
\text { on the fit between the } \\
\text { organization and the } \\
\text { implementation } \\
\text { contingencies. }\end{array}$ \\
\hline $\begin{array}{l}\text { (Choi et } \\
\text { al., 2007) }\end{array}$ & $\begin{array}{l}\text { Mail } \\
\text { Questionnaire }\end{array}$ & 236 & $\begin{array}{l}\text { The importance of training } \\
\text { of end users significant for } \\
\text { successful ERP } \\
\text { implementation, however } \\
\text { companies still have } \\
\text { relatively low budgets and } \\
\text { do not focus significantly } \\
\text { on these issues. }\end{array}$ \\
\hline
\end{tabular}


Another perspective on the investments in ERP systems that organizations undertake is the link between the perceived performance of the firm, and the association of these returns with the ERP systems [4]. One of the difficulty that the managers face when dealing with the issues of financial performance as a factor of adoption of ERP systems is that these systems in most cases are chosen due to their ability to show clear profits, However, in many cases the benefits of the ERP systems are not accrued properly, which means that all the benefits of these systems are not taken into account [4] This can in many cases lead to the lack of adoption of ERP systems, as managers are unable to justify the relatively high costs of systems based on only financial performance. Taking into account other factors as surrogate variables for the financial performance may be a significant way of improving these difficulties; however it has largely been ignored in the literature [4].

\section{DISCUSSION}

After examining the main aspects of the review of literature, we argue that the adoption of the ERP systems is positively associated with increased financial performance. This is based on the assumption that organizations need to justify the cost outlays of new ERP system and need to undertake a number of other factors which lead to the adoption of ERP system. The review of literature has led to the development of five main propositions, which will be analyzed in the light of the literature and the theories presented in the earlier section. These propositions are as follows:

\section{A. Proposition One: User Training and Education has a Positive Influence on the Perceived Benefits for Users of ERP}

User training seems to be one of the key issues which have led to the resistance to change from the users perspectives. A clear understanding of the real needs of the users to adopt the different systems is needed by the senior management, and need $s$ to be taken into account to ensure that this is part of the adoption process. Research suggests that the benefits of a satisfied user is highly significant for the adoption of the system, as the user is able to take part in the implementation of the system and the resistance to change from the user is kept to a minimum. Another critical component of the user training during the implementation of a system is that the training environment which the management provides is also part of a collective leaning process [39], [60].

The review of the literature on the training aspects however fails to raise a number of issues which have been observed in other parts of the information systems literature. For example, a critical component of the systems development literature indicates that the best way to improve the training aspects of the user is to ensure that the involvement of the user in the development process of the ERP is significant. However, the literature on ERP and associated training regimes tends to ignore it. We propose that any future research agenda should seek to associate the training and education needs of the user with the development of new ERP systems[60], [36], as this would ensure that the user is able to be an active part of the system development process, and then will be more likely to be benefit from system. In this regard, the TAM is particularly beneficial as it can lead to improving the benefits of training for the user, leading to earlier adoption of new technologies such as ERP. One of the established facts of the literature within the training and education issues which ERP adoption highlights is based on the notion of the perceived benefits of ERP users[36], [37]. The research highlights that the user is able to take up ERP systems with more enthusiasm if they have been properly training, and this therefore needs to be one of the future research agendas of academic in this field.

The training element for the information systems usage is a critical component of the implementation of the ERP systems and needs to be implemented in a successful system [38]. However, one of the critical aspects of the information systems implementation is that most of the companies have lower training budgets for their information systems [38], and the focus of the organization is to cut training costs. However, some of these constraints are being reduced by using innovative training methods such as web based training approaches, which can be used to improve the training environment in an innovative manner [38]. Another critical training issue is the use of information technology within different domains such as education is also of significant importance. Information systems specialists needs to ensure that the gaining competitive advantage by implementing ERP's in interactive and educational contexts can also be a source of improving the adoption of the end user, and the role of the IT would be to ensure that these systems are implemented in a proper manner within these constraints [38]. The level of learner satisfaction is also a relevant issue for satisfying the needs of the users of ERP systems [38]. The satisfaction that users receive from the training teat they receive is also of critical importance for the organization, as it can be a significant factor in the relative success or failure of the information system [38]. Change management is also a critical component of the technology acceptance model, as it allows the management to align the different aspects of the change management processes and therefore to ensure that the organization can cope with the changes being brought about by the acceptance of the new technologies in the organization [61]. In this regard, the acceptance of technology by the users can be based on the internal issues such as the culture of the organization, and on other external issues such as the environment within which the organization operates [62].

\section{B. Proposition Two Change Management has a Positive Influence on the Perceived Benefits for the Organization}

Change management, is highly rated as one of the key factors which inhibits the adoption of ERP at the organizational level. The traditional literature on the resistance to change has also been tested with the implementation of ERP, and it shows that change management remains one of the key issues which manager need to deal with. On the level of the users, one of the key issues which they have faced is the problems they perceive when a new system is being implemented [42], [43], [46]. Universally, it seems that the user of the system or the 
employees in many cases, are reluctant to welcome a new system as they associate these system with job losses and changes in the power structure arrangements in an organization. The key underlying aspect of the change management seems to be uncertainty in the organizational environment [13], [63], [45]. The effort of the senior management must be focused on decreasing the uncertainty, which can also be undertaken by implementing a technology acceptance model, which examines the ways in which new technology can be accepted by the users of a system.

We also propose that change management be one of the key dimensions of the perceived benefits of the ERP implementation and adopting by organization, as it can lead to either a smooth or bumpy adoption process. The acceptance by the academic community about the importance of change management as a future research issues which takes into account the technology acceptance model by the organization would also mean that further research can be carried out which examines the reasons for the resistance to change found in the organizational atmosphere [64], [43]. Another critical component of the change management process in an organization is the way in which the different organizations need to take into account the cultural and behavioral aspects of the change management process, which would present a more complete picture of the benefits of for the organization through the adoption of the ERP systems. Another major aspect of the change management process is a link between the TAM and its implications within the change management process during ERP implementation. A future research agenda could also be based on developing the link between the change management processes in an organization. This research needs to focus on developing organizational factors which can seek to explain

The benefits which ERP users can derive are based on their acceptance of the technologies. This is in particular important as it allows the managers to plan the implementation of systems, and therefore also allows the improvements in the financial system, which can bring process efficiency to the organization [65]. This can also benefit the different organizations, as the change management acceptance and the acceptance of the new technologies can improve the effectiveness of the organization, as well as making it easier for mangers to implement their plans [65]. One of the particular benefit of the new technologies is that the managers can develop a system, where the change management process becomes part of the technology acceptance procedure in the organization, which can facilitate the entire process, and ensure that the different aspects of the organizational procedures [66]. In many cases, the aim of the origination is to ensure that the entire process is smooth, which can lead to fewer issues during the management of the different aspects of change.

\section{Proposition Three the Perceived Benefits for the Organization have a Positive Impact on Improved Financial Performance}

We propose that there is a clear link between the benefits for the organization when adopting ERP and improve financial performance. Our research suggests that the intangible benefits which an organization receives as part of the adoption of ERP are not recorded properly, and are difficult to measure. The financial performance of ERP, is thus in most cases undervalued, as the benefits from ERP are far and wider in their scope than simple benefits of cost cutting. Although empirical evidence is needed to support these claims, research does suggest that the measurement of the long term and intangible benefits have proven to be highly successful [57] measures of the ERP adoption by different organization, and should be taken into account. On a different level, the adoption of ERP is also highly challenging as in many cases even the tangible benefits are not measured by the organization. There is a need by organization to measure these benefits to get an accurate estimate of the different kinds of benefits which organizations receive as part of their investment in ERP systems [34], [51].

The reduction in the lead time and the improvements in customer service have been identified as some of the key benefits of the ERP for the organization, leading to the increased adoption of the systems in the wider context of long term benefits. The tangibility and quantification of the variables are then seen as the most important aspect for the organization, as this enables them to undertake informed decision making regarding the ERP adoption in their own settings.

The benefits to the organization also were to be balanced within the technology acceptance model. The technology acceptance model in this regard is of the view that there is a need for the different components of the system to be properly accepted by all the stakeholders, if the organization wants to get the rewards of the system [67]. The aim of the managers should therefore be that the ERP system, which is normally organizational in nature, and can involve the different components of the supply chain, is implemented in way that all the stakeholders are able to take part in the implementation. This will enable the true benefits of the customer service to be realized, as the technology is increasingly accepted by the many different

\section{Proposition Four the Perceived Benefits of Users have a Positive Influence on Improved Financial Performance}

The other side of the story seems to indicate that the organizations is the not the only stakeholder in having a positive financial impact during the adoption of ERP [8], [9] adoption. Another critical component of the adoption story of the ERP seems to be the benefits that the users receive, and the positive financial impact of these benefits on the organization. User satisfaction is a significant issue for the adoption of the systems by the end user, which also seems to translate into positive financial contribution for the organization. Research suggest that the satisfaction of the user can also be increased if the user is part of the development process of a system, and is able to communicate with many of the different stakeholders in this process. The role of the user must be supported by the senior management, and one of our suggestions is that it should be within the techno logy acceptance model, which helps the managers to decide to take the best course of action for the organizational benefits as a strategic advantage mechanism.

Another considerable issue is that the financial 
performance due to increased user benefits needs to be measured accurately. In many cases, the ERP system has hidden benefits for the user [4], [68], [69]. For example, the user may not be aware that the ordering system is enabling them to use just in time methods, which not only reduces the costs for the organization, but also reduces the work load for the user. In such situation, the quantification of the systems and their perceived benefit are very difficult to quantify, and therefore a more improved financial modeling system is needed to take the wider financial benefits of the system into account. Another critical component of the development of the users interests is to ensure that their cultural needs are also satisfied, which would impact the overall financial profitability of the adoption of the ERP effort by the organization. This is a critical proposition within this research agenda, as it would ensure that the failure of systems within ERP are averted, and that the long term financial needs of the organization to reduce costs awhile also improving the level of customer services is undertaken successfully [28], [29]. One of the key components of the ERP implementation is that it not only enables the implementation of the integrated systems, but also enables the organization to improve their service levels and standards due to the automation of the processes. However, the benefits that the user receive from the adoption of ERP systems, in general should be taken into account while also including the hidden benefits, which enables a more broader and level judgment regarding the success or failure of the system.

\section{E. Proposition Five Improved Financial Performance of ERP Systems has a Positive Impact on ERP Acceptance.}

The justification for the investments which managers undertake in an organizational environment is generally based on feasibility studies. The decision to go ahead with a particular investment is generally based on whether the system or process, in the long run would be able to deliver a profitable return. The focus of the managers seem to be on the value that ERP's add to their organizational environment, with a commitment to take up ERP systems where they are financially viable. However, or observations suggest that the adoption of ERP systems should take into consideration two main components. Firstly, the adoption of ERP systems should be based on the hard accounting evidence that the system will be financially viable [32], [33], and enable the organization to lower its costs or improve its profitability. However, we also suggest that a second and main component of this model should be based on the need to undertake and evaluate the intrinsic value which ERP add to an organizational environment. In many cases, ERP is the base line system in the organization, and many decision support and executive level systems are based on the data that ERP system generates and gathers. There is a need for organization to take a strategic view when evaluating the financial benefits of the system, and ensure that they do not misjudge the total benefits of ownership of ERP systems, as it would enable the development and implementation of many new processes in the organizational environment, which would enable the organization to develop a robust system, which also enables it to achieve a long term competitive advantage. Another component with in the financial viability of the new systems during times of other organizational needs [70]-[73]. In such cases, we suggest that the research agenda within ERP adoption should seek to examine the conflicting needs of the organizational actors, and to develop a more balanced approach for the decision making processes in the organization

The acceptance of the new technology, it appears is directly associated with the financial performance of the organization. Users are more likely to adopt a new technology, when they feel that a particular technology can benefit the organization more, and therefore can lead to financial rewards for the organization and the employees [22], [66]. These in particular would be accepted by the different employees of the organization, and therefore establishes a clear link between TAM and the financial performance of a company on the ERP acceptance.

\section{CONCLUSIONS}

This paper attempts to provide a theoretical foundation on the adoption of ERP systems and their association with the financial performance of the organization, especially focusing in relation to the TAM. The rationale for the implementation of the ERP systems in different organizations has been a confusing set of factors, which have been highlighted by the literature. This paper, has attempted to suggest a set of propositions, which we believe are the key underlying factors which can be taken into account by organizations when they are trying to implement new ERP systems. One of the key conclusion of this research is that although financial performance is one of the key initiative for the organizations to adopt new ERP systems, other factors such as user satisfaction and the need to account for the many indirect benefits from the system also need to be taken into account to understand the dynamics of ERP adoption in organizations.

One of the key factors which need to be taken into account is the user satisfaction, which has also been highlighted in TAM. This seems to be the key initiative which the organizations need to take into account for a successful implementation of ERP systems in organization today, as the success or failure of these systems is highly dependent on the ways in which users adopt the systems. This user satisfaction process is based on a comprehensive training schedule of the user. The organizations need to ensure that the training regimes of the user are in line with the cultural and psychological needs of the user, which would ensure a harmony in the implementation process. The literature on the user training also suggest that the perceived benefits which users receive from a system can be improved if they are better educated and informed about the system. The notion of resistance to change can also be reduced as the implementation of the system includes the explicit and the implicit needs of the user. One of the key conclusions of this research is that the future research agenda needs to give more emphasis on the training needs of the user to ensure that the ERP acceptance process is smoother and more beneficial to all the parties in the process.

Another significant conclusion of this research is that one of the significant issues, which have been under researched in 
the ERP acceptance process, is change management and its influence on the organizational actors. Although significant literature is present on the issues of change management from the perspective of the end user, the organizational perspective is mostly missing. Our research suggests that the need to include change management as a key research item in the different aspects of ERP adoption is also critical because of the involvement of the senior management in the change process, which needs to be fully behind the ERP implementation process for it to be successful. The change management process is an integral part of the ERP adoption, as the adoption of new systems leads to a period of uncertainty about the jobs, processes and the political structure of the organization, which traditionally leads to resistance to change form the different actors of the organizational structure. A better understanding especially with the framework of the technology acceptance model would enable the future researchers to evaluate the wider needs of the different stakeholders in the organizational environment.

Another major conclusion of this research is that the benefits for the organization should be clear for any ERP implementation initiative to be successful. In this regards, we find that there needs to be a clear distinction in the tangible and intangible returns on the investment that organizations undertake for the adoption of ERP systems. ERP systems must be able to deliver clear results, as a confusion of the rate of return can only lead to increased resistance to change form the top managers, which are unable to justify the rewards of implementing the ERP systems. Another significant observation of this research is that the managers must also clearly show the intangible returns and benefits of ERP acceptance for the organization. This is highly important for organizations, As the clear demarcation of the different types of financial returns from the ERP adoption would ensure that the system can deliver of these benefits, and they can be part of the benefits which are associated with the ERP systems. There is a need to further examine the different effects that the strategic level of benefits have on the adoption process, and the benefits it brings to the organization in the long run. This would not only enable the managers to be able to make more informed decisions regarding the applicability of ERP adoption processes in a strategic and competitive analysis of the organizations.

Another considerable conclusion of this research is that the benefits which users receive can also lead to significant financial improvements due to the adoption of ERP systems. One of the key benefits of satisfying the end user would be that the user would be able to adopt the systems in a more robust and tempered manner, which would lead to the increase in the productivity of the user. Such changes in the benefits which the user derives from the system would in effect also lead to improvements in the financial performance of the organization, and to ensure that the system is not just about cost cutting, but also improving the quality of service and standards. One of the most important aspects in this regard is the way in which the increased needs of the user benefits need to be measured accurately too. The different types of needs of users, if measured correctly when adopting a new ERP system would also enable the organization to deliver a system that is consistently better performing and accepted by all the different stakeholders. This also is true if we examine this proposition in view of the technology acceptance model. The acceptance of the technology by the user is critical, which then can lead to significant financial benefits for the organizations.

This research has proposed a particular research agenda and proposition which support the adoption of ERP through the means of examining it within the cannon of financial performance. This conclusion has been reached for a particular reason; which is that the ultimate aim of the organizational actors is to ensure that the organization is able to profit. Any evaluation of a technology without examining the ultimate financial benefits that the organization can receive from it, we think is fruitless exercise. Therefore, we propose that the future research on ERP should focus on the financial performance of the company. However, a significant research result of this research is that organizations always need to take into account the tangible and intangible financial benefits of ERP adoption, and develop more clear measures to quantify these variables. The future research direction needs to ensure that although user satisfaction, training and other issues are important, the ultimate decision factor in the success or failure of a system is the financial returns which an particular ERP system generates. There is a need for the researchers to ensure that all long term, strategic and indirect benefits of the ERP system implementation are taken into account, which would ensure that a more fair and just approach to the adoption decision making is prevalent organizations. This approach, we prose should also take into account the technology acceptance model, however within a financial performance model. This would be a more balanced method for assessing the ways in which the adoption of ERP system is undertaken in organizations, especially once the managers understand the ways in which technologies are accepted by the users.

\section{REFERENCES}

[1] Y. Li, "ERP adoption in traditional Chinese SMES: An exploratory case study," 2010.

[2] M. L. Markus, S. Axline, D. Petrie, and C. Tanis, "Learning from adopters' experiences with ERP: Problems encountered and success achieved," Journal of Information Technology, vol. 15, no. 4, pp. 245-265, 2000.

[3] B. McNurlin, "Information technology - will users of ERP stay satisfied," MIT Sloan Management Review, vol. 42, no. 2, pp. 13, 2001.

[4] K. E. Murphy and S. J. Simon, "Intangible benefits valuation in ERP projects," Information Systems Journal, vol. 12, no. 4, pp. 301-320, 2002.

[5] M. Plaza and K. Rohlf, "Learning and performance in ERP implementation projects: A learning-curve model for analyzing and managing consulting costs," International Journal of Production Economics, vol. 115, no. 1, pp. 72-85, 2008.

[6] J. Y. Yeh and Pacis, "ERP implementation and organization changes," 2005, pp. 1506-1512

[7] S. S. Chen and L. B. Liu, "Measure of ERP users' satisfaction," in Proc. IEEE International Conference on Service Operations and Logistics, and Informatics, 2008, vol. 2, pp. 1980-1985.

[8] L. L. Hsu and Y. T. Weng, "Critical factors effect user satisfaction and impact of ERP system," in Proc the 11th Annual Conference of Asia pacific Decision Sciences Institate, 2006, pp. 234-238.

[9] P. Longinidis and K. Gotzamani, "ERP user satisfaction issues: Insights from a greek industrial giant," Industrial Management \& Data Systems, vol. 109, no. 5-6, pp. 628-645, 2009. 
[10] A. N. Talet and H. Agourram, "The analysis of user involvement in development and implementation of computerized information systems and perceived usefulness - case study in Saudi Arabia," 2008.

[11] F. D. Davis, "Perceived usefulness, perceived ease of use, and user acceptance of information technology," Mis Quarterly, vol. 13, no. 3, pp. 319-340, 1989.

[12] K. A. Gyampah and A. F. Salam, "An extension of the technology acceptance model in an ERP implementation environment," Information and Management, vol. 41, no. 6, pp. 731-745, 2004.

[13] C. Bozarth, "ERP implementation efforts at three firms-integrating lessons from the sisp and it-enabled change literature," International Journal of Operations and Production Management, vol. 26, no. 11-12, pp. 1223-1239, 2006.

[14] M. K. Chang, W. Cheung, C. H. Cheng, and J. H. Y. Yeung, "Understanding ERP system adoption from the user's perspective," International Journal of Production Economics, vol. 113, no. 2, pp. 928-942, 2008.

[15] G. Chen, Y. Sai, and J. Zhang, "ERP implementation strategies based on critical success factors," 2009

[16] V. Venkatesh, M. G. Morris, G. B. Davis, and F. D. Davis, "User acceptance of information technology: Toward a unified view," MIS Quarterly, vol. 27, no. 3, pp. 425-478, 2003.

[17] S. Dasgupta, M. Granger, and N. McGarry, "User acceptance of e-collaboration technology: An extension of the technology acceptance model," Group Decision and Negotiation, vol. 11, no. 2, pp. 87-100, 2002.

[18] S. Demetriadis, A. Barbas, A. Molohides, G. Palaigeorgiou, D. Psillos, I. Vlahavas, I. Tsoukalas, and A. Pombortsis, "Cultures in negotiation: Teachers' acceptance/resistance attitudes considering the infusion of technology into schools," Computers and Education, vol. 41, no. 1, pp 19-37, 2003.

[19] M. Calnan, D. Montaner, and R. Horne, "How acceptable are innovative health-care technologies? A survey of public beliefs and attitudes in England and Wales," Social Science and Medicine, vol. 60, no. 9, pp. 1937-1948, 2005.

[20] C. D. Chen, Y. W. Fan, and C. K. Farn, "Predicting electronic toll collection service adoption: An integration of the technology acceptance model and the theory of planned behavior," Transportation Research Part C-Emerging Technologies, vol. 15, no. 5, pp. 300-311, 2007.

[21] A. Ronteltap, J. C. M. van Trijp, R. J. Renes, and L. J. Frewer, "Consumer acceptance of technology-based food innovations: Lessons for the future of nutrigenomics," Appetite, vol. 49, no. 1, pp. 1-17, 2007.

[22] C. M. Bruhn, "Enhancing consumer acceptance of new processing technologies," Innovative Food Science and Emerging Technologies, vol. 8, no. 4, pp. 555-558, 2007.

[23] W. J. Crump, R. J. Tessen, and A. J. Montero, "The department without walls-acceptability, cost, and utilization of interactive video technology," Archives of Family Medicine, vol. 6, no. 3, pp. 273-278, 1997.

[24] A. Tinker and P. Lansley, "Introducing assistive technology into the existing homes of older people: Feasibility, acceptability, costs and outcomes," Journal of Telemedicine and Telecare, vol. 11, pp. 1-3, 2005.

[25] S. L. Fisher and A. W. Howell, "Beyond user acceptance: An examination of employee reactions to information technology systems," Human Resource Management, vol. 43, no. 2-3, pp. 243-258, 2004.

[26] J. H. Wu, W. S. Shen, L. M. Lin, R. A. Greenes, and D. W. Bates, "Testing the technology acceptance model for evaluating healthcare professionals' intention to use an adverse event reporting system," International Journal for Quality in Health Care, vol. 20, no. 2, pp. 123-129, 2008.

[27] L. Lapointe and S. Rivard, "Getting physicians to accept new information technology: Insights from case studies," Canadian Medical Association Journal, vol. 174, no. 11, pp. 1573-1578, 2006.

[28] M. Daneva and R. Wieringa, "Cost estimation for cross-organizational erp projects: Research perspectives," Software Quality Journal, vol. 16, no. 3, pp. 459-481, 2008.

[29] R. J. Kusters, F. J. Heemstra, and A. Jonker, "Determining the costs of ERP implementation," 2007.

[30] R. J. Kusters, F. J. Heemstra, and A. Jonker, "ERP implementation costs: A preliminary investigation," in FILIPE, J. C. J. C. J. ed. Enterprise information systems-books, 2008.

[31] P. Kelle and A. Akbulut, "The role of ERP tools in supply chain information sharing, cooperation, and cost optimization," International Journal of Production Economics, vol. 93, no. 4, pp. 41-52, 2005.
[32] S. I. Chang, S. Y. Hung, D. C. Yen, and P. J. Lee, "Critical factors of ERP adoption for small- and medium- sized enterprises: An empirical study," Journal of Global Information Management, vol. 18, no. 3, pp. 82-106, 2010

[33] Y. Hwang, "Investigating the influence of cultural orientation and innovativeness on ERP adoption," Journal of Global Information Technology Management, vol. 14, no. 3, pp. 54-74, 2011.

[34] C. C. H. Law and E. W. T. Ngai, "ERP systems adoption: An exploratory study of the organizational factors and impacts of ERP success," Information and Management, vol. 44, no. 4, pp. 418-432, 2007.

[35] K. A. Gyampah, "Perceived usefulness, user involvement and behavioral intention: An empirical study of ERP implementation," Computers in Human Behavior, vol. 23, no. 3, pp. 1232-1248, 2007.

[36] A. Noudoostbeni, N. M. Yasin, and H. S. Jenatabadi, "A mixed method for training ERP systems based on knowledge sharing in Malaysian Small and Medium Enterprise (SMEs)," in Proc. IEEE International Conference on Information Management and Engineering, 2009.

[37] J. E. Scott, "Post implementation usability of ERP training manuals The user's perspective," Information Systems Management, vol. 22, no. 2, pp. 67-77, 2005.

[38] D. H. Choi, J. Kim, and S. H. Kim, "ERP training with a web-based electronic learning system: The flow theory perspective," International Journal of Human-Computer Studies, vol. 65, no. 3, pp. 223-243, 2007.

[39] A. Bhattacherjee and C. Sanford, "Influence processes for information technology acceptance: An elaboration likelihood model," MIS Quarterly, vol. 30, no. 4, pp. 805-825, 2006.

[40] M. Y. Yi, J. D. Jackson, J. S. Park, and J. C. Probst, "Understanding information technology acceptance by individual professionals: Toward an integrative view," Information and Management, vol. 43 , no. 3 , pp. $350-363,2006$

[41] G. M. Cao and M. McHugh, "A systemic view of change management and its conceptual underpinnings," Systemic Practice and Action Research, vol. 18, no. 5, pp. 475-490, 2005.

[42] S. Foster, P. Hawking, and C. Zhu, "The human side of ERP implementations: Can change management really make a difference?" in Research and Practical Issues of Enterprise Information Systems II, vol. 1, 2008.

[43] M. M. Ghilan, "ERP systems and dealing with resistance to change," 2009.

[44] B. Stumm, "Change management in large-scale enterprise information systems," in GRUST, Current Trends in Database Technology, 2006.

[45] I. Visoiu, "Aspects of change management for integrated management systems," 2005.

[46] S. Foster, "A new approach to change management in enterprise system implementations," 2006.

[47] J. S. Luo, D. M. Hilty, L. L. Worley, and J. Yager, "Considerations in change management related to technology," Academic Psychiatry, vol. 30, no. 6, pp. 465-469, 2006.

[48] D. M. DeJoy, "Behavior change versus culture change: Divergent approaches to managing workplace safety," Safety Science, vol. 43, no. 2, pp. 105-129, 2005.

[49] E. Y. Cheng and Y. J. Wang, "Business process reengineering and ERP systems benefits," 2006.

[50] P. Hawking, Benefit Realisation and ERP Systems, 2003.

[51] R. J. Kolz and Isa, "Benefits of integrating plant data with ERP," in Proc. Conference on Instrumentation, Systems, and Automation, 2002.

[52] T. L. Legare, "The role of organizational factors in realizing ERP benefits," Information Systems Management, vol. 19, no. 4, pp. 21-42, 2002.

[53] F. Wu, C. Liu, H. Z. Li, K. Gao, and J. Tian, "The benefits evaluation of ERP project investment based on real options," in Proc. IEEE International Conference on Systems, Man, and Cybernetics, vol. 1-6, 2006.

[54] C. W. Holsapple and M. P. Sena, "ERP plans and decision-support benefits," Decision Support Systems, vol. 38, no. 4, pp. 575-590, 2005.

[55] Y. J. Xue, H. G. Liang, W. R. Boulton, and C. A. Snyder, "ERP implementation failures in China: Case studies with implications for ERP vendors," International Journal of Production Economics, vol. 97, no. 3, pp. 279-295, 2005

[56] I. Im, Y. Kim, and H. J. Han, "The effects of perceived risk and technology type on users' acceptance of technologies," Information and Management, vol. 45, no. 1, pp. 1-9, 2008.

[57] M. R. M. Torres, S. L. T. Marin, F. B. Garcia, S. G. Vazquez, M. A. Oliva, and T. Torres, "A technological acceptance of e-learning tools used in practical and laboratory teaching, according to the European higher education area," Behaviour and Information Technology, vol. 27, no. 6, pp. 495-505, 2008. 
[58] Z. Q. Zhu, "A systems approach to developing and implementing an ERP financial subsystem," Systems Research and Behavioral Science, vol. 23, no. 2, pp. 237-250, 2006.

[59] C. Ranganathan and C. V. Brown, "ERP investments and the market value of firms: Toward an understanding of influential ERP project variables," Information Systems Research, vol. 17, no. 2, pp. 145-161, 2006.

[60] A. A. Samaha, H. Tamimi, and S. Yousef, "Perceptions of information technology/information systems value/utilisation in Saudi organizations," 2007.

[61] S. C. L. Koh, A. Gunasekaran, and J. R. Cooper, "The demand for training and consultancy investment in SME-specific ERP systems implementation and operation," International Journal of Production Economics, vol. 122, no. 1, pp. 241-254, 2009.

[62] P. Legris, J. Ingham, and P. Collerette, "Why do people use information technology? A critical review of the technology acceptance model," Information and Management, vol. 40, no. 3, pp. 191-204, 2003.

[63] I. Adamson and J. Shine, "Extending the new technology acceptance model to measure the end user information systems satisfaction in a mandatory environment: A bank's treasury," Technology Analysis and Strategic Management, vol. 15, no. 4, pp. 441-455, 2003.

[64] A. Taroata, M. Tamasila, I. Taucean, and A. Pugna, "Changes in SME's: Technological development versus ERP implementation," 2007.

[65] P. Cybulski, J. Zantinge, and D. A. McNeil, "Embracing technology? Using change management strategies to improve the use of continuous lateral rotation therapy," Dynamics (Pembroke, Ont.), vol. 17, no. 3, pp. 28-32, 2006

[66] R. Walczuch, J. Lemmink, and S. Streukens, "The effect of service employees' technology readiness on technology acceptance,' Information \& Management, vol. 44, no. 2, pp. 206-215, 2007.

[67] R. J. Holden and B. T. Karsh, "The technology acceptance model: Its past and its future in health care," Journal of Biomedical Informatics, vol. 43, no. 1, pp. 159-172, 2010.

[68] A. L. Lederer, D. J. Maupin, M. P. Sena, and Y. L. Zhuang, "The technology acceptance model and the world wide web," Decision Support Systems, vol. 29, no. 3, pp. 269-282, 2000.
[69] A. D. A. Santos, J. S. A. de Lima, and E. C. B. C. Filho, "Benefits of ERP implementation systems in brazil businesses: Case studies," 2010.

[70] S. S. C. and L. B. L. "An empirical analysis on ERP improving user's decision-support benefits: Evidences from key users," 2008.

[71] R. Meissonier, E. Houze, and N. Belbaly, "The IT culture as an obstacle to the adoption of an ERP: Case of a high-tech SME," 2007.

[72] Y. Song, J. Han, D. Cheng, and Y. Zhang, "An empirical research on the impact of CSFS on adoption of ERP," 2007.

[73] C. Suebsin and N. Gerdsri, "Technology adoption: A case study of ERP implementation in one of healthcare organizations in Thailand," 2010.

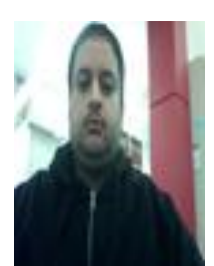

Ayman Bazhair is currently a $\mathrm{Ph} . \mathrm{D}$ candidate in the UNE business school at the University of New England my thesis is factor of adoption of enterprise resource planning (ERP) system and their impact on Saudi Arabia listed companies.

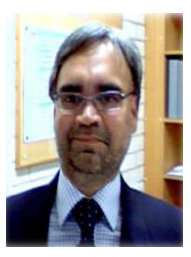

Kamaljeet Sandhu teaching and research expertise are in information systems adoption, management accounting and corporate governance adoption, and e-learning acceptance at universities. He is an active researcher and has widely published in international conferences such as ECIS, ACIS, PACIS, and journals which include International Journal of Business Information Systems (IJBIS); Journal of Electronic Customer Relationship Management (IJECRM); International Journal of Innovation and Learning (IJIL); and book chapters in Advances in Computer and Information Sciences and Engineering, Sobh, Tarek (Ed.), Publisher: Springer, New York, USA; and Lecture Notes in Computer Science, Publisher: Springer Berlin / Heidelberg. He serves as a member of professional associations and University Committeesa 